\title{
Influence of internal parallel and v-shaped ribs on the discharge coefficient of a cylindrical film cooling hole
}

\author{
C Heneka*, A Schulz, and H-J Bauer \\ Institute of Thermal Turbomachinery, Karlsruhe Institute of Technology, Karlsruhe, Germany
}

\begin{abstract}
An experimental study has been conducted to investigate the discharge behaviour of cylindrical film cooling holes with the main focus on the effects of rib arrangement and crossflow velocity inside the internal cooling passage of a gas turbine blade. Two straight flow channels of rectangular cross-section simulate the crossflow situations present at the inlet and outlet of a film cooling hole. The two channels are connected by a single scaled-up film cooling hole with a diameter of $10 \mathrm{~mm}$, an inclination angle of $30^{\circ}$, and a length-to-diameter ratio of 6 . Measurements have been performed at various internal crossflow Mach numbers and rib geometries for both parallel and perpendicular orientations of internal and external crossflows. Parallel and v-shaped ribs with quadratic cross-section and four different angles with respect to the internal crossflow direction $\left(45^{\circ}, 60^{\circ}, 75^{\circ}\right.$, and $\left.90^{\circ}\right)$ have been placed upstream and downstream of the entrance of the hole at one wall of the cooling passage. The rib height equals the hole diameter, the rib pitch to height ratio is 10 . The internal crossflow Mach number has been varied between 0 and 0.37 .

The data show that placing ribs onto the wall of the coolant passage may result in reduced, unchanged, or even increased discharge coefficients. Internal crossflow Mach number and orientation of the coolant passage in respect to the hole axis have been identified as major influencing parameters.
\end{abstract}

Keywords: turbomachinery, film cooling, discharge coefficient, crossflow, turbulators

\section{INTRODUCTION}

To increase thermal efficiency of modern gas turbines, greater efforts have been put on the improvement of cooling technology of the first-stage turbine over the past three decades. Highest overall cooling efficiency at turbine vanes and blades can be achieved by a combination of internal and external cooling techniques. To enhance the convective heat transfer in the internal cooling passages, which are typically designed as meanders (multi-pass or

\footnotetext{
*Corresponding author: Institute of Thermal Turbomachinery, Karlsruhe Institute of Technology, Kaiserstrasse 12, 76128 Karlsruhe, Germany.

email: christian.heneka@kit.edu
}

serpentine cooling), the internal walls are provided with turbulators. Most common in any design are ribs, pins, and dimples.

Most of the studies dealing with ribbed channels focus on the friction factor and the heat transfer distribution inside the channel [1]. Within these studies, several geometric parameters have been varied besides characteristic flow parameters like Reynolds number, rotation number, and buoyancy number. It has been found that some of the geometric factors interact intensely, so that for an optimum internal cooling design, combination effects have to be taken into account. Extensive studies have been performed by J-C Han and co-workers at Texas A\&M University, investigating parameters such as the channel aspect ratio (AR) [2], rib pitch, and height [1], as well as rib 
angle [3] and shape [4]. They concluded that a smart placement of ribs might enhance heat transfer by a factor of up to 5 compared to smooth wall conditions. However, this positive aspect of rib placement comes always along with a penalty regarding the friction factor.

For various reasons, internal convective cooling alone might not be sufficient to meet the limits of the material temperature. Therefore, additional external film cooling is utilized. The cooling film is generated by coolant fed through discrete holes that are connected to the previously described internal coolant passages. An important aspect in this context, which is addressed by this study, is the impact of internal ribs on the through-flow behaviour of the cooling holes and, consequently, on the performance of the cooling film.

The parameters describing a film cooling configuration are the discharge coefficient, the film cooling effectiveness, and the heat transfer coefficient. The discharge coefficient is a measure for the flow losses occurring at the entrance, inside, and at the exit of the hole. It specifies the mass flux through the hole under given conditions and is defined as the ratio of the actual mass flux and an ideal mass flux according to equation (1). The ideal mass flux is calculated assuming an isentropic one-dimensional expansion. The driving pressure is the difference between the total pressure in the coolant passage and the static pressure at the exit of the hole.

$$
\begin{aligned}
& c_{\mathrm{D}}=\frac{\dot{m}_{\text {actual }}}{\dot{m}_{\text {ideal }}} \text { with } \quad \dot{m}_{\text {ideal }}=\frac{p_{\mathrm{tc}}}{\sqrt{ } R T_{t c}} \cdot \frac{\pi}{4} D^{2} \cdot \Phi \\
& \Phi=\left(\frac{p_{m}}{p_{t c}}\right)^{\frac{(\kappa+1)}{2 \kappa}} \sqrt{\frac{2 \kappa}{(\kappa-1)} \cdot\left[\left(\frac{p_{t c}}{p_{m}}\right)^{\frac{(\kappa) 1)}{\kappa}}-1\right]}
\end{aligned}
$$

In the recent past, a significant number of studies have been performed to investigate the influence of various geometric as well as aerodynamic factors on the discharge coefficient. A comprehensive review of published data has been given by Hay and Lampard [5]. Cylindrical holes have been tested by Burd and Simon [6] regarding the hole length to diameter ratio, and by Hay et al. [7] and Gritsch et al. [8] regarding the inclination angle, the lateral hole angle, and the influence of internal and external crossflows. Different hole shapes in combination with crossflow have been presented by Hay and Lampard [9], Gritsch et al. [10] and Saumweber and Schulz [11]. In Saumweber and Schulz [12], discharge coefficients of fan-shaped holes with varying angles of inclination are presented. Correlations predicting the discharge coefficient including the effects of internal and external crossflows have been developed by Hay et al. [13] and Gritsch et al. [14] for cylindrical holes and by
Gritsch et al. [15] for fan-shaped holes. In Rowbury et al. [16] discharge coefficients without crossflow have been correlated and subsequently corrected by additive loss coefficients to assess the effect of external crossflow.

In spite of the large number of investigations concerning the discharge coefficient of film cooling holes, less attention has been given to the influence of the geometry of internal channels with turbulators. Concerning the influence of ribs on film cooling parameters, only few investigations have been published. The influence of guiding ribs at the entrance of the hole on film cooling effectiveness downstream of the exit of the hole is presented in Wilfert and Wolff [17]. In Kissel et al. [18], the influence of $45^{\circ}$ internal ribs on the external heat transfer coefficient and film cooling effectiveness has been investigated.

In Bunker and Bailey [19], the effect of internal ribs on the discharge coefficient of a cylindrical hole has been studied. They showed that the position of the hole relative to the ribs and the crossflow direction significantly affect the discharge coefficient. In a recently published study of Heneka et al. [20], an internal coolant passage featuring parallel $90^{\circ}$ ribs with a rib height to hole diameter ratio of unity has been used. Discharge coefficients as a function of the rib position relative to the hole inlet in combination with various internal crossflow velocities and hole angles are presented. Additionally, a correlation has been developed including all the parameters mentioned.

\section{EXPERIMENTAL SET-UP}

The tests have been carried out in a continuous operating wind tunnel at the Institute of Thermal Turbomachinery at Karlsruhe Institute of Technology. The internal and external crossflow situations, present at the hole inlet and exit regions of a film cooling hole, have been simulated by two channels of rectangular cross-section. The external channel (width $\times$ height $=90 \times 45 \mathrm{~mm}^{2}, \mathrm{AR}=1.5: 1$ ) is directly supplied by the high-pressure-high-temperature facility (HPHT). A detailed description of the used facility (Fig. 1, left) is given by Wittig et al. [21]. Since this study concentrates on the discharge behaviour only, the high-temperature capability of the HPHT facility was not required. As the density ratio has no effect on the discharge coefficient $[\mathbf{1 4}]$, the tests were performed under isothermal conditions, i.e. main flow (hot gas) temperature and coolant temperature are kept at the same level of $300 \mathrm{~K}$.

The internal channel $\left(70 \times 50 \mathrm{~mm}^{2}, \mathrm{AR}=1.4: 1\right)$ is part of a secondary loop with one inlet and the cooling hole as the only outlet. The loop is also supplied 

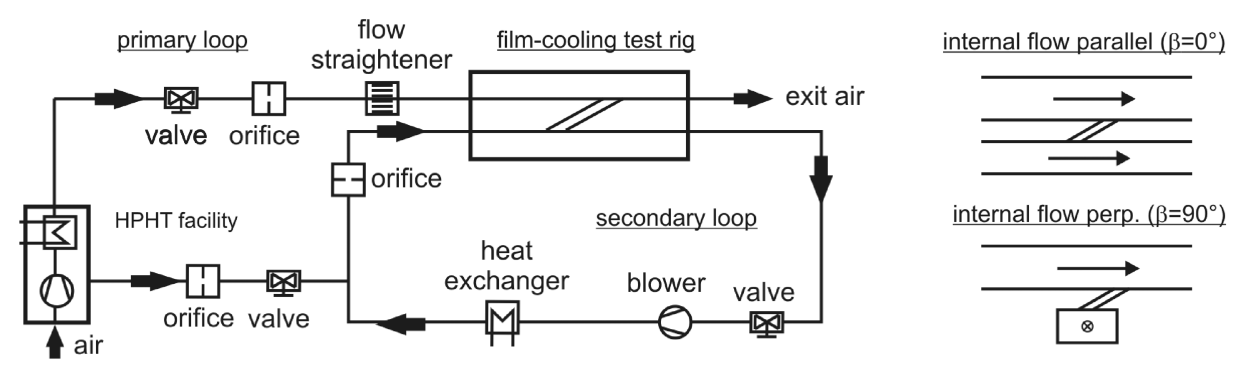

Fig. 1 Test facility and flow orientation
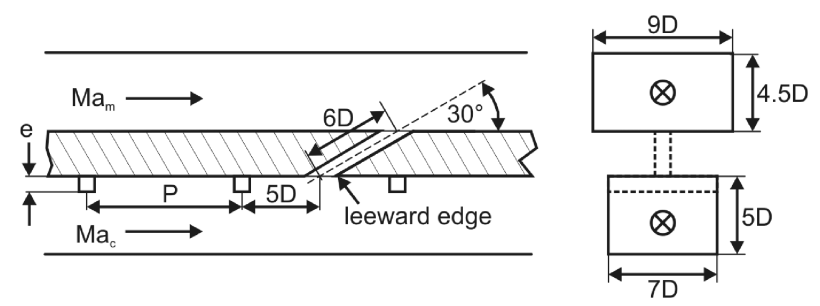

Fig. 2 Definition of hole and rib geometry

by the HPHT facility. The flow inside the loop is driven by an extra blower and temperature conditioned (removal of enthalpy from the blower). By doing so, two decisive advantages have been realized. First, the static pressure and the Mach number of the coolant crossflow at the hole inlet can be adjusted independently. Second, the mass flux through the film cooling hole can be measured directly with a high accuracy by an orifice at the supply to the secondary loop.

For the different tests, the internal and the external channels have been oriented parallel $\left(\beta=0^{\circ}\right)$ and perpendicular $\left(\beta=90^{\circ}\right)$ to each other (Fig. 1, right), representing the flow situation in a turbine blade and vane, respectively. They are connected by a scaledup film cooling hole with a diameter $(D)$ of $10 \mathrm{~mm}$. The hole has an inclination angle $(\alpha)$ of $30^{\circ}$ and a length-to-diameter ratio, $L / D$, of 6 (Fig. 2). During the design process of the test rig, numerical calculations have been performed, including the internal channel and its inlet section. The results for three selected rib designs showed a periodic internal flow after the fourth rib. Thus, in total, seven ribs have been inserted into the internal channel with the hole inlet positioned in the middle between the fifth and sixth ribs, as marked in Fig. 3, for the different rib configurations. All ribs are sharp edged and have a quadratic cross-section with an engine typical edge length, $e / D$, of 1 , resulting in a blockage of the internal channel of 20 per cent due to the ribs. The pitch to edge length ratio, $P / e$, is 10 . Ribs have been placed only at the top wall of the internal channel.
Therewith, the actual channel design represents the upper half of an internal channel with a typical rib height of 10 per cent of the channel height, assuming symmetry of the internal flow. The validity of this assumption has been checked in a numerical prestudy where the flow field around the ribs have been compared for internal channels with two opposite ribbed walls in in-line as well as in staggered rib arrangement and for half of an internal channel with one ribbed wall only.

The internal rib configurations tested within this study differ in shape and orientation of the ribs relative to the internal crossflow (Fig. 3). Parallel ribs with four different angles of attack $\left(45^{\circ}, 60^{\circ}, 75^{\circ}\right.$, and $90^{\circ}$, with respect to the internal crossflow direction) and $\mathrm{v}$-shaped rib with three different angles $\left(45^{\circ}, 60^{\circ}\right.$, and $75^{\circ}$ ) have been examined. The entire variations of the ribs have been tested at a parallel orientation of internal and external crossflows; the parallel ribs have been tested additionally for a perpendicular orientation. The crossflow Mach number of the free stream flow has been kept constant $\left(M a_{\mathrm{m}}=0.3\right)$. The turbulence level and the boundary layer thickness at the location of the hole exit have been measured prior to the discharge coefficient measurements using hot wire anemometry. The internal crossflow Mach number has been varied from $M a_{\mathrm{c}}=0$ (plenum conditions) to $M a_{\mathrm{c}}=0.37$, leading to a maximum internal Reynolds number related on the hole diameter which is equal to the rib height - of $R e_{\mathrm{D}, \mathrm{c}} \approx 150000$.

Mach numbers have been determined using the static and total pressures of the coolant flow and mainflow, respectively. The total pressure of the mainflow has been measured using a Pitot probe, located $5 D$ upstream of the hole exit at $1 D$ off the centre plane of the channel. The static pressure is detected by means of a pressure tap included into the side wall of the channel at identical streamwise position as the Pitot probe. An identical combination of a Pitot probe and a wall pressure tap is located inside the coolant channel $2.5 \mathrm{D}$ below the cooling hole inlet. Discharge coefficients have been 


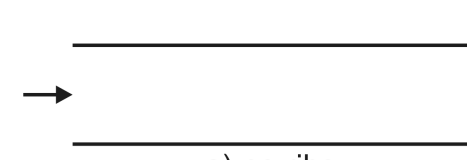

a) no ribs

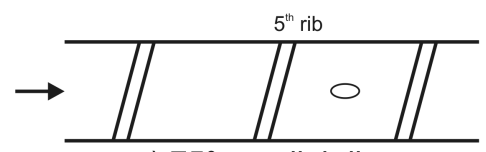

c) $75^{\circ}$ parallel ribs

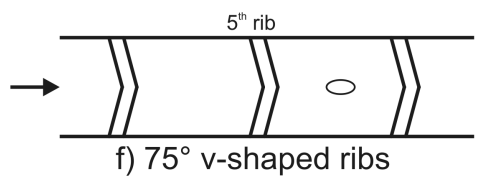

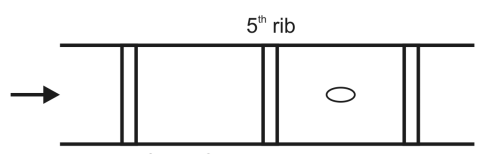

b) $90^{\circ}$ parallel ribs

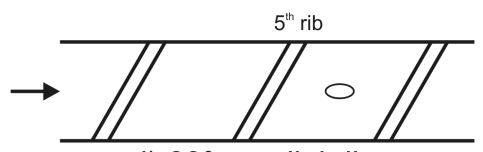

d) $60^{\circ}$ parallel ribs

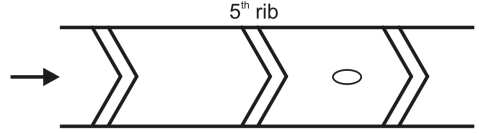

g) $60^{\circ} \mathrm{v}$-shaped ribs

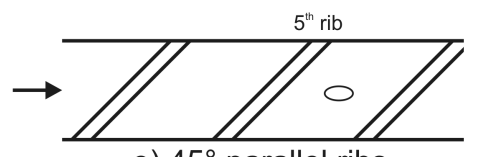

e) $45^{\circ}$ parallel ribs

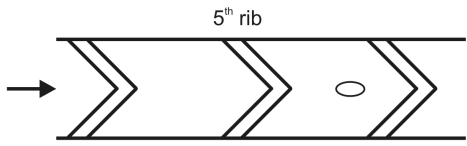

h) $45^{\circ} \mathrm{v}$-shaped ribs

Fig. 3 Tested rib configurations

Table 1 Operating conditions

Free stream Mach number

Internal Mach number

Internal Reynolds number

Pressure ratio

Free stream turbulence intensity

Boundary layer thickness

Temperature ratio

determined from measured pressure ratios (PRs). Since the PR is defined as the ratio of total pressure at the entrance of the hole and static pressure at the hole outlet, discharge coefficients are only available for values of PR greater than 1.0 for higher internal Mach numbers. A summary of the operating conditions is given in Table 1.

\section{ESTIMATE OF ACCURACY}

Uncertainties have been estimated according the procedure proposed by Kline and McClintock [22]. The uncertainty in setting up the Mach number can be calculated to be less than 1 per cent. Due to the design of the secondary loop, the actual flowrate through the hole could be measured by means of a standard orifice having an uncertainty of 2 per cent except for very low mass flowrates. The uncertainty in determining the ideal mass flowrate can be calculated to be less than 4 per cent, coming from the uncertainty of the hole diameter of about 2 per cent. Thus, the overall uncertainty for the discharge coefficient amounts up to 4.5 per cent except for very low mass flowrates.

\section{RESULTS}

Results of the actual study compared to literature data of Hay et al. [7], Bunker and Bailey [19], and Saumweber and Schulz [11] are shown in Fig. 4. For low PRs $(<1.3)$, the discharge coefficients for the cases without ribs (square symbols) match quiet good. At higher PRs, the values of the actual study are about 10 per cent lower. Comparing cases with ribbed internal channels (circular symbols), it can be seen that the discharge coefficients measured by Bunker and Bailey [19] are somewhat higher than the results of the actual study. The deviance might by caused by the different configurations as in Bunker and Bailey [19], a shorter cooling hole $(L / D=4)$ without external crossflow $\left(M a_{\mathrm{m}}=0\right)$ was used.

Before coming to the discussion of the effect of internal rib configuration on the discharge coefficient at internal crossflow conditions, the flow characteristics at the entrance of an inclined film cooling hole have to be discussed both for parallel and perpendicular orientations of internal crossflow and hole axis.

As described in Gritsch et al. [14] and Rowbury et al. [16], the loss mechanism inherent to a film cooling hole can be divided into inlet, internal, and exit losses. As the mainflow conditions and the hole geometry are constant for all test cases, it can be assumed that the latter two losses are constant in the actual study with a length-to-diameter ratio $(L / D)$ of the hole of 6 . Thus, in the following cases, a change in the discharge coefficient can be exclusively attributed to the losses occurring at the hole inlet.

The flow at the inlet region of an inclined cooling hole is highly affected by the internal flow conditions. In case of internal plenum conditions $\left(M a_{\mathrm{c}}=0\right)$, a separation bubble forms at the leeward edge of the hole inlet due to the deflection of the coolant when entering the hole. The size of the separation bubble and therewith the losses are independent of the orientation of the internal channel. Consequently, as shown in Fig. 5, the discharge coefficient for the two examined orientations of coolant supply channel and hole axis at internal plenum $\left(M a_{\mathrm{c}}=0\right)$ conditions match 


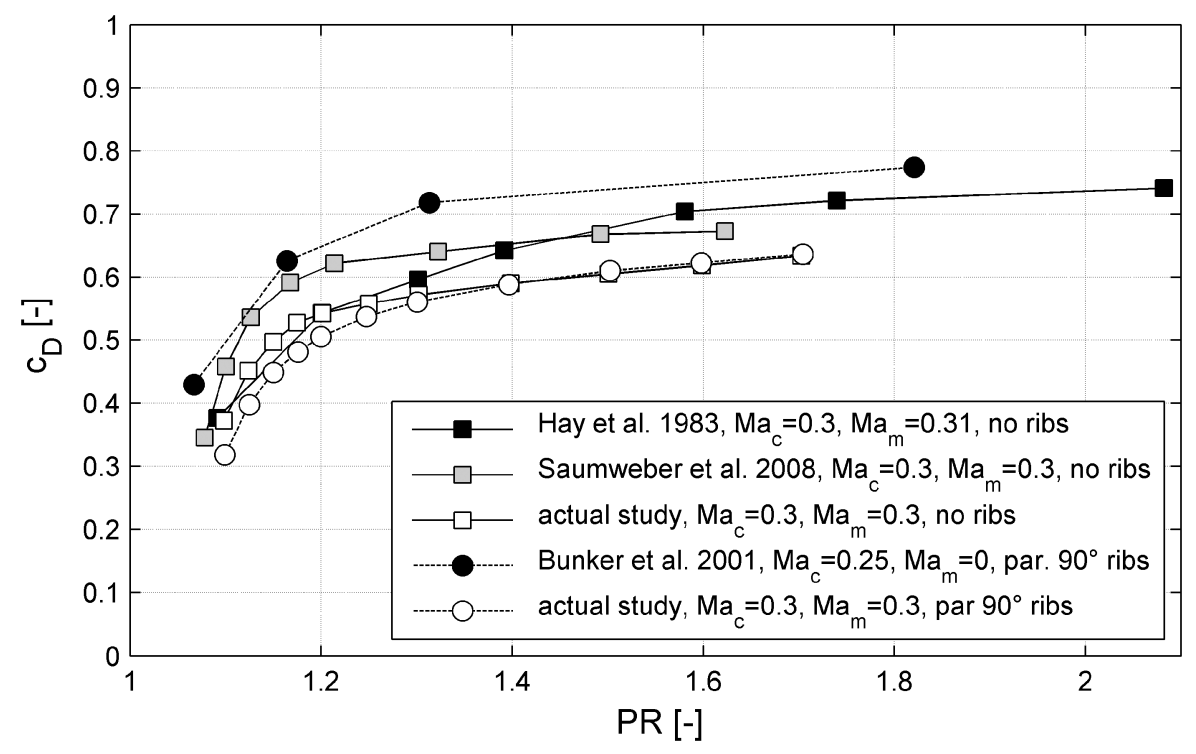

Fig. 4 Comparison with literature data, perpendicular orientation $\left(\beta=90^{\circ}\right)$

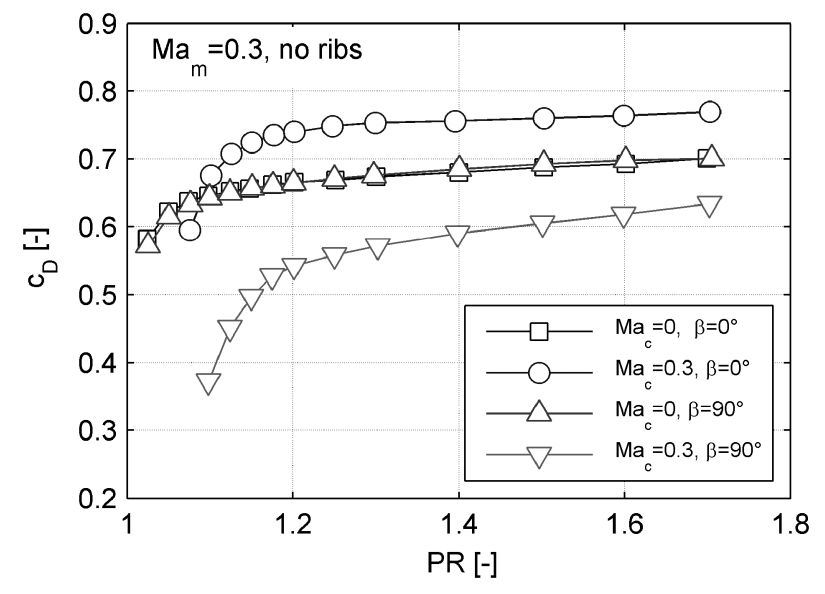

Fig. 5 Discharge coefficient versus PR, no ribs

perfectly, indicating, in addition, considerable repeatability of the experiments. When crossflow is present, the situation changes. At a parallel orientation of coolant crossflow and hole axis and at a crossflow Mach number of $M a_{\mathrm{c}}=0.3$, the discharge coefficient is increased (Fig. 5), whereas in case of a perpendicular orientation $\left(\beta=90^{\circ}\right)$ and identical crossflow velocity, the discharge coefficient is highly reduced. This behaviour is caused by the different flow fields at the hole inlet region for the two described crossflow orientations.

At a parallel orientation, crossflow induces an additional momentum into the hole, thereby reducing the size of the separation bubble at the leeward edge and consequently the inflow losses. If this would be the only loss mechanism, one would expect further growing discharge coefficients with even higher crossflow

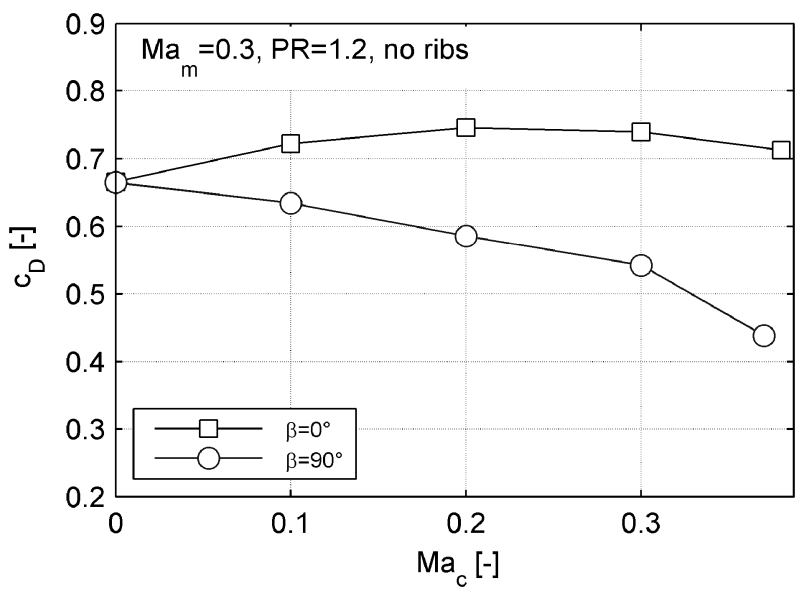

Fig. 6 Discharge coefficient versus crossflow Mach number, no ribs, $\mathrm{PR}=1.2$

velocities. For higher crossflow velocities, however, a second separation bubble forms at the windward edge of the hole inlet [8], causing flow losses in this region. By means of the data presented in Fig. 6, where the discharge coefficient is plotted versus internal crossflow Mach number at a constant PR of 1.2, the optimum Mach number for a parallel orientation can be estimated to be in a range between $0.2<M a_{\mathrm{c}}<0.3$. This is in agreement to the results found in Gritsch et al. [8]. In contrast, at perpendicular orientation, the coolant crossflow has no velocity component in the direction of the hole axis; thus, the separation bubble at the hole inlet and subsequently the inlet losses are increased with enhanced crossflow velocity. Consequently, the discharge coefficient 


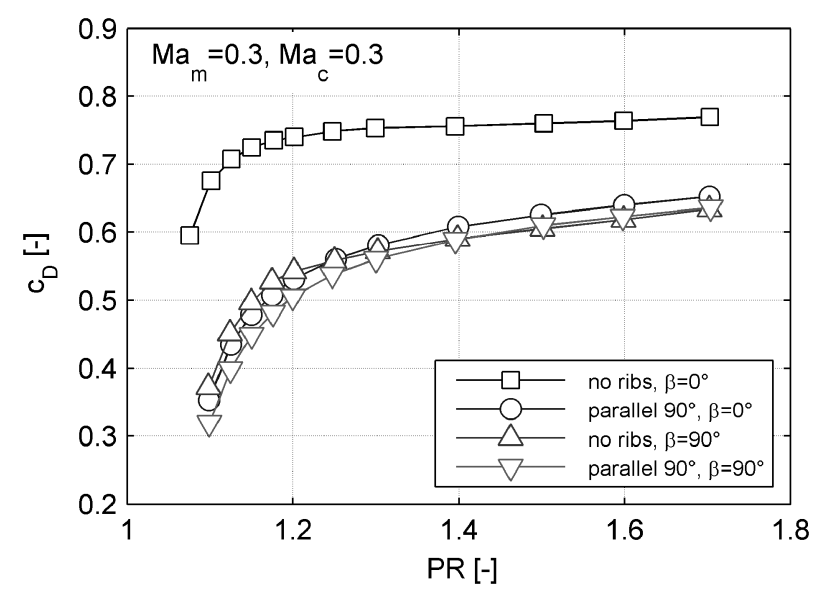

Fig. 7 Discharge coefficient versus PR, effect of parallel $90^{\circ}$ ribs

decreases monotonously with increasing crossflow Mach number.

Additional internal ribs change the flow situation at the hole inlet, the dimension of the separation bubble, and, thus, the discharge coefficient for the crossflow cases. In Fig. 7, the effect of $90^{\circ}$ parallel ribs on the discharge coefficient for two different orientations of internal supply channel at constant crossflow Mach number of $M a_{\mathrm{c}}=0.3$ is shown. For parallel orientation $\left(\beta=0^{\circ}\right)$, the ribs cause an immense drop of about 30 per cent at a PR of 1.2 and of 20 per cent for higher PRs. For a perpendicular orientation, almost no influence of the additional ribs can be detected; the discharge coefficient remains at a very low level.

An explanation for this behaviour can be found by observing the aerodynamic flow characteristics at the hole inlet for the different configurations. As mentioned earlier, the crossflow induces an additional momentum into the hole in case of parallel orientation of internal supply channel and hole axis, thereby reducing the size of the leeward separation bubble. Consequently, the discharge coefficient is increased. This positive effect seems to be no longer present in the case of ribbed walls. The flow around the square ribs is schematically shown in Fig. 9. In Acharya et al. [23] and Ahn et al. [24], the arising flow features have been detected experimentally and numerically, respectively. At the windward edge of the first rib, the flow separates and forms a recirculation region downstream of the rib. The distance of two following ribs with a pitch of $P / e=10$ is such that the flow reattaches between the two ribs. Several investigations (for example 1) have shown that for $90^{\circ}$ parallel ribs with a quadratic cross-section, this rib pitch offers a good compromise in respect to the relevant internal quantities, namely, the heat transfer coefficient and

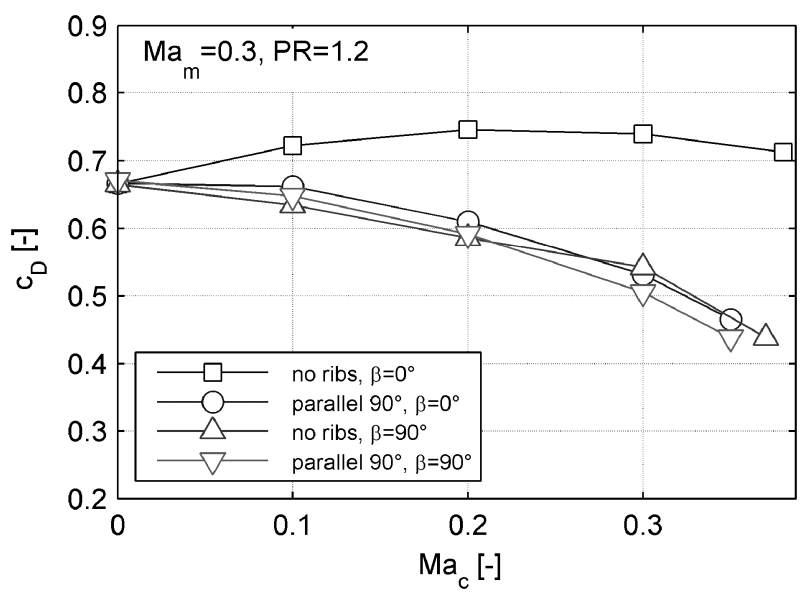

Fig. 8 Schematic view of flow around parallel $90^{\circ}$ ribs

the friction factor in square channels. In front of the next rib, the flow detaches again from the wall, forming a small vortex at the foot of this rib.

A question regarding the consequences of these characteristics when the inlet of an inclined film cooling hole is located in between two such ribs arises. Two main effects can be identified. On the one hand, the streamwise velocity component near the wall at the hole inlet is strongly reduced compared to the case without ribs, reducing the additional momentum due to the crossflow. On the other hand, the recirculation region downstream of the first rib might extend beyond the hole entry, causing a separation bubble at the leading edge of the hole inlet. Both effects account for the strong reduction of the discharge coefficient compared to the situation without ribs.

In the case of perpendicular orientation of the coolant supply channel and the hole axis, a separation bubble forms at the lateral edge of the hole inlet, regardless of whether $90^{\circ}$ parallel ribs are present in the coolant supply channel or not. The losses occurring at the hole inlet seem to not depend on the changed flow situation due to the ribs, and the corresponding discharge coefficients (Fig. 7) do not change. Surprisingly, the discharge coefficient found for the case with ribs at a parallel orientation of internal crossflow and hole axis and the one found for the cases with and without ribs at a perpendicular orientation are approximately at an identical level. That means that the absolute values of the inflow losses, although caused by different effects, are comparable. This behaviour is valid for the whole range of internal Mach numbers tested, as can be seen in Fig. 9, where the discharge coefficient is plotted versus internal crossflow Mach number at a constant PR of 1.2 for $90^{\circ}$ parallel ribs at two orientations. The discharge 


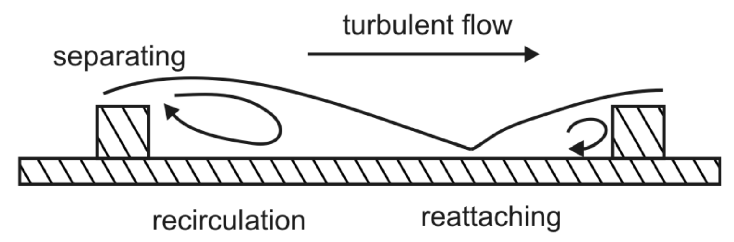

Fig. 9 Discharge coefficient versus crossflow Mach number, effect of parallel $90^{\circ}$ ribs
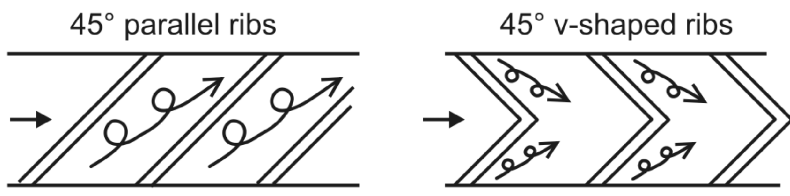

Fig. 10 Secondary flow patterns forming at inclined parallel and $\mathrm{v}$-shaped ribs

coefficient decreases monotonously with increasing crossflow velocity for the three cases described.

\subsection{Effect of parallel ribs at parallel orientation $\left(\beta=0^{\circ}\right)$}

Some arguments account for the inclination of the internal ribs relative to the crossflow direction. First of all, the overall internal heat that can be removed from the internal surface is increased due to the enhanced surface area as well as increased heat transfer coefficients. Second, the friction factor can be influenced by inclined ribs. Han et al. [3] have shown that the heat transfer coefficient is drastically enhanced for parallel $45^{\circ}$ ribs compared to parallel $90^{\circ}$ ribs, whereas the friction factor remains almost constant. They found the induced secondary flows to be responsible for this increase. However, further investigations $[2,4]$ have shown that the effect of the rib inclination angle strongly depends on the channel AR. In case of narrow channels (AR 1:4, 1:2, and 1:1) $60^{\circ}$ parallel ribs perform best with respect to heat transfer augmentation, whereas for wider ones (AR 2:1 and 4:1), $90^{\circ}$ ribs lead to highest values. In contrast, the friction factor penalty is highest for $60^{\circ}$ ribs.

Having the findings from the previous paragraph in mind, it can be expected that the secondary flows also affect the inflow into a film cooling hole, inducing losses and consequently reducing the discharge coefficient. To quantify the losses, the influence of the rib angle on the discharge coefficient for parallel ribs at an internal crossflow Mach number of $M a_{\mathrm{c}}=0.3$ is shown in Fig. 11. First of all, it can be seen that the discharge coefficient is strongly affected by the rib angle at high internal crossflow conditions. Lowest values have been found for the already discussed

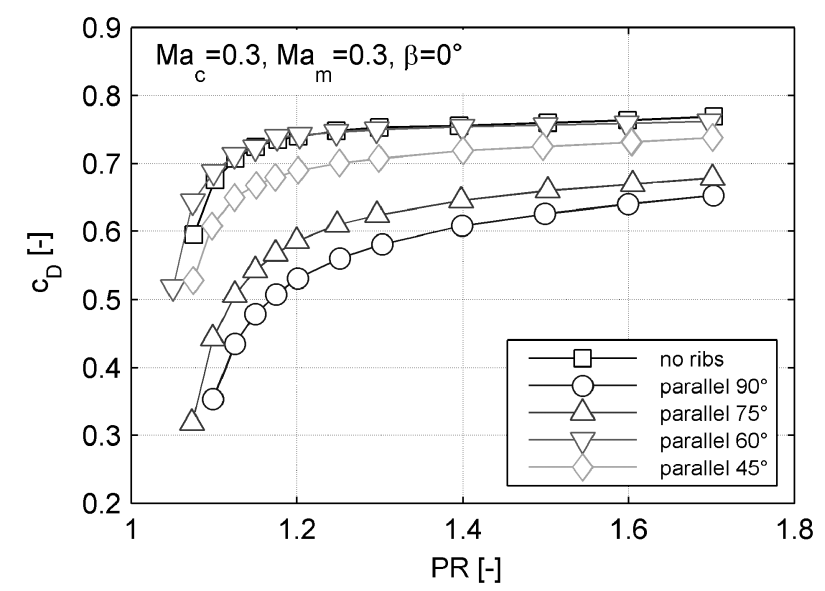

Fig. 11 Discharge coefficient versus PR, parallel ribs, $M a_{\mathrm{c}}=0.3, \beta=0^{\circ}$

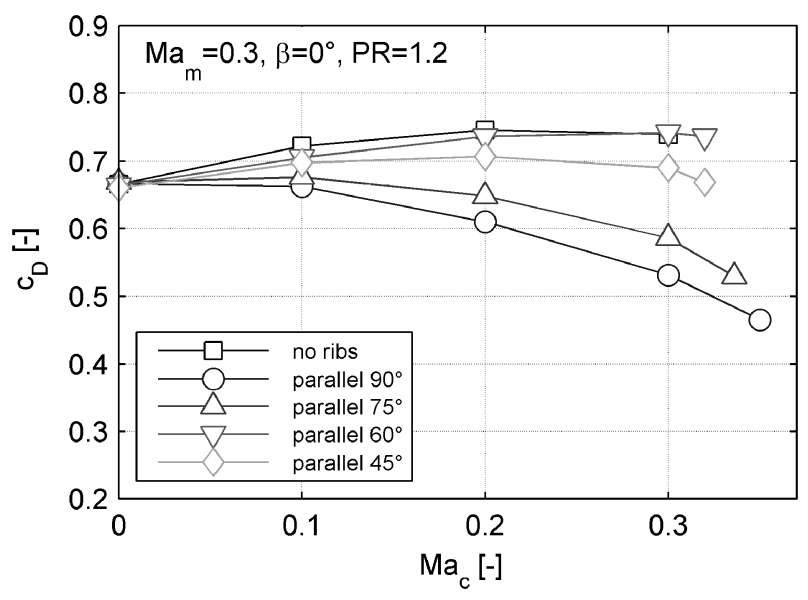

Fig. 12 Discharge coefficient versus crossflow Mach number, parallel ribs, $\mathrm{PR}=1.2, \beta=0^{\circ}$

case with $90^{\circ}$ parallel ribs and highest ones for the case without ribs and, surprisingly, for $60^{\circ}$ angled ribs. Hence, decreasing the angle of attack from $90^{\circ}$ to $60^{\circ}$ improves the inflow into the cooling hole, decreases the developing losses, and thus increases the discharge coefficient. A further reduction of the rib angle to $45^{\circ}$ leads to a slight reduction. It seems that the secondary flow structures forming downstream of inclined ribs positively affect the inflow into $30^{\circ}$ inclined holes by including a momentum in hole axis direction (Fig. 10).

Figure 12 shows that the observed behaviour is not only valid for an internal Mach number of $M a_{\mathrm{c}}=0.3$ but over the entire range of measured crossflow velocities. In contrast to the configuration where ribs are angled $90^{\circ}$ and $75^{\circ}$ relative to the internal crossflow, the discharge coefficient of the even more inclined ribs $\left(45^{\circ}\right.$ and $\left.60^{\circ}\right)$ first increases with 


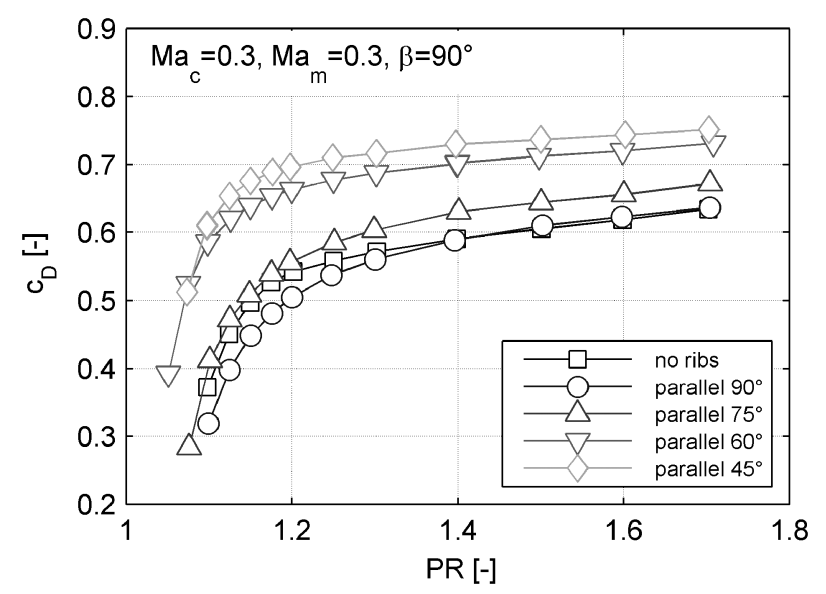

Fig. 13 Discharge coefficient versus PR, parallel ribs, $M a_{\mathrm{c}}=0.3, \beta=90^{\circ}$

increasing crossflow Mach number. Similar to the case without ribs, an optimum can be found for medium crossflow velocities, before a decline can be observed at further increased velocities. The difference between the rib angles is most pronounced for the highest crossflow Mach numbers measured.

\subsection{Effect of parallel ribs at perpendicular arrangement $\left(\beta=90^{\circ}\right)$}

Different behaviours can be found in case of perpendicular orientation of the coolant supply channel and the hole axis. As described earlier, the discharge coefficient is decreased drastically with internal crossflow, as a separation forms at the hole inlet region which is increasing with crossflow velocities. Inserting parallel ribs with an angle relative to the crossflow direction into the coolant supply channel leads to secondary flow patterns in between the ribs. If those secondary flow schemes include velocity components into the hole at the inlet region, the losses might be reduced and enhanced discharge coefficient compared to the non-ribbed case could be expected. Observing the discharge coefficients for different rib angles presented in Fig. 13, this effect is clearly visible.

Decreasing the angle of attack of the inclined ribs increases the discharge coefficient consequently. Particularly, for the $45^{\circ}$ and $60^{\circ}$ ribs, very high levels of discharge coefficient comparable to the best performance at parallel orientation of internal crossflow and hole axis could be detected. Again, when plotting the discharge coefficient for these cases versus internal crossflow Mach number at a constant PR (Fig. 14), the increasing influence of the rib angle with rising internal Mach number becomes obvious. Whereas the discharge coefficient monotonously decreases with internal Mach number for rib angles of $75^{\circ}$ and

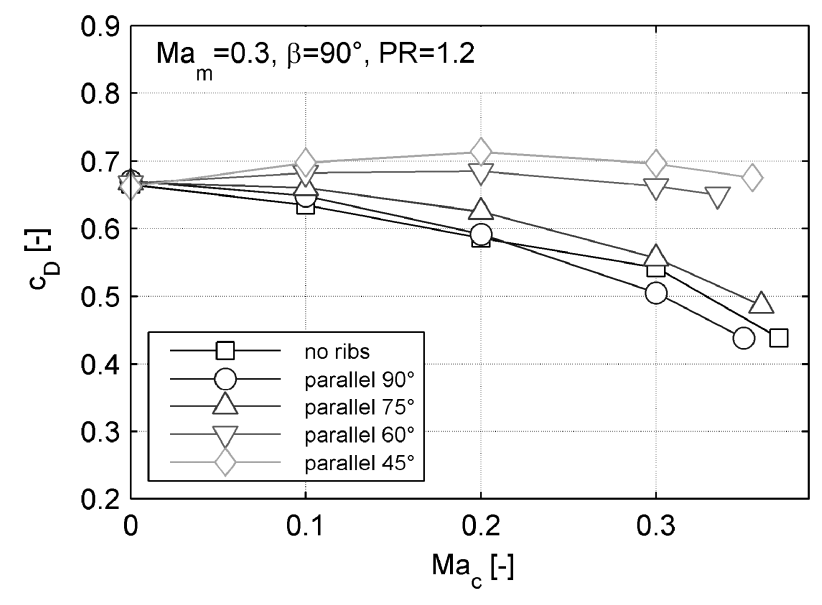

Fig. 14 Discharge coefficient versus crossflow Mach number, parallel ribs, $\mathrm{PR}=1.2, \beta=90^{\circ}$

$90^{\circ}$ as well as for the non-ribbed case, an optimum Mach number in the midrange of measured Mach numbers can be found for $60^{\circ}$ and $45^{\circ}$ angled ribs. Apparently, the secondary flow patterns caused by the inclined ribs first promote and then hinder the inflow into the hole. Generally, it can be stated that the discharge coefficient for the latter two rib angles remains at a very high level for all internal crossflow conditions, showing a beneficial behaviour on this influencing parameter compared to the cases without ribs.

\subsection{Effect of $v$-shaped ribs at parallel orientation $\left(\boldsymbol{\beta}=\mathbf{0}^{\circ}\right)$}

V-shaped, forward-oriented ribs in combination with some channel ARs are known to improve heat transfer in the internal channel compared to parallel ribs [4]. This enhancement results from the formation of two secondary flow schemes along the two legs of the arrow shape (Fig. 10). Velocity components are induced from the outer part into the centre part of the channel. In some configurations, these secondary flows might include a beneficial velocity component at the inlet region of a cooling hole positioned between two ribs. Thus, additional discharge coefficient measurements have been conducted for $\mathrm{v}$-shaped ribs and a parallel orientation. Figure 15 shows the influence of the rib angle of $v$-shaped ribs on the discharge coefficient at an internal crossflow Mach number of $M a_{\mathrm{c}}=0.3$. Lowest values of the discharge coefficient have been measured for $75^{\circ}$ $\mathrm{v}$-shaped ribs. They are almost exactly the same as the values found for parallel $90^{\circ}$ ribs which are given as reference in the plot. Decreasing the angle of attack of the v-shaped ribs leads to an enhancement of the discharge coefficient. The curve for the 


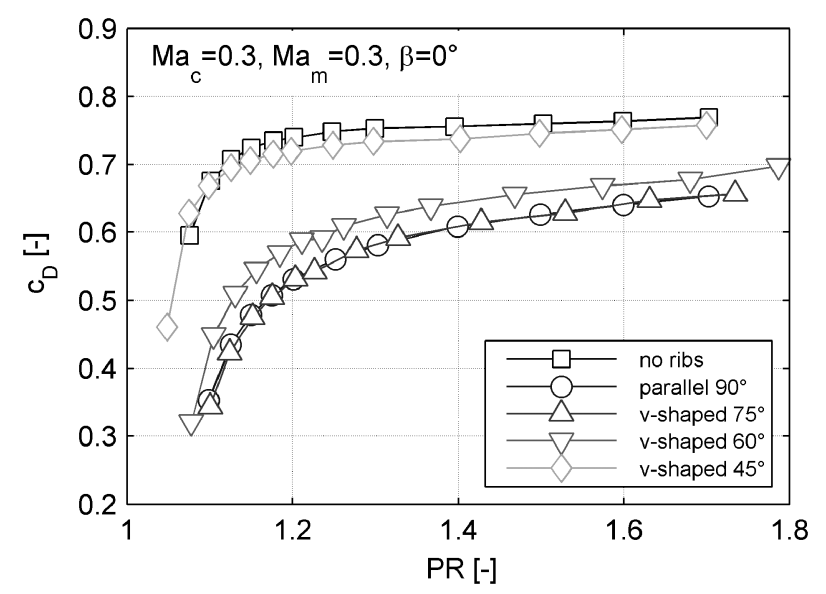

Fig. 15 Discharge coefficient versus PR, v-shaped ribs, $M a_{\mathrm{c}}=0.3, \beta=0^{\circ}$

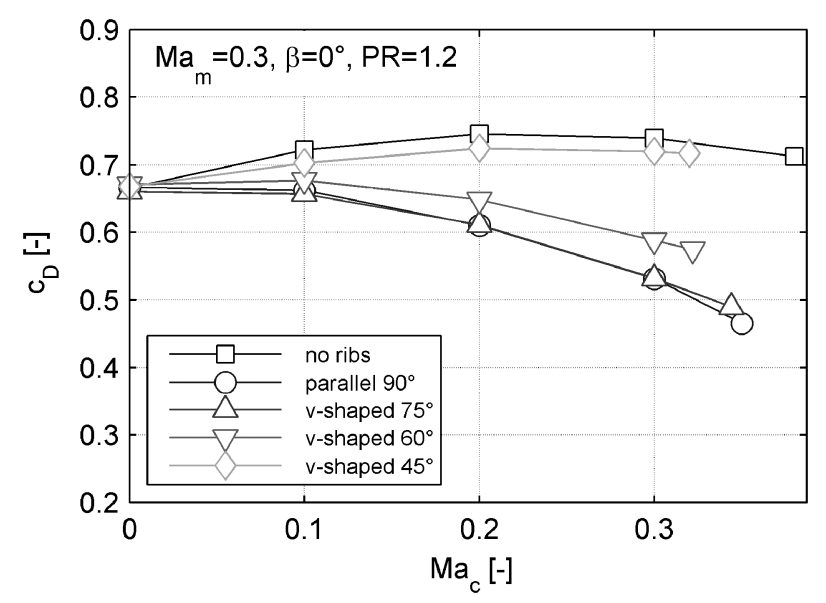

Fig. 16 Discharge coefficient versus crossflow Mach number, $\mathrm{v}$-shaped ribs, $\mathrm{PR}=1.2, \beta=0^{\circ}$

$\mathrm{v}$-shaped ribs angled $45^{\circ}$ to the internal crossflow direction even approach the values found for the unribbed case, which have been found to provide highest discharge coefficients for parallel arrangement in this study.

For reasons of completeness, the discharge coefficient of different v-shaped ribs versus internal crossflow velocity at a constant PR of 1.2 is plotted in Fig. 16. As found earlier for other combinations of crossflow orientations and rib shape, some rib angles $\left(75^{\circ}\right.$, $60^{\circ}$ ) show a monotonously decreasing discharge coefficient with increasing crossflow Mach number, whereas the $45^{\circ} \mathrm{v}$-shaped rib case has an optimum internal Mach number in the midrange $\left(M a_{\mathrm{c}}=0.2-0.3\right)$.

\section{CONCLUSION}

An experimental study is presented with main focus on the influence of internal coolant supply channel geometry on the discharge coefficient of a $30^{\circ}$ inclined cylindrical film cooling hole. Seven different internal rib geometries and - for reasons of comparison - the non-ribbed reference case have been investigated over a wide range of engine-typical internal crossflow conditions, i.e. crossflow Mach number and PR over the hole. The following conclusions can be drawn.

1. Flow losses at the inlet region of an inclined hole are primarily caused by a flow separation forming due to deflection of the coolant entering the hole.

2. The size of the separation bubble and thus the flow losses are reduced when the flow conditions at the hole inlet region provide an additional momentum in hole axis direction. This additional momentum could either be caused directly by the internal crossflow or by secondary flow patterns forming due to the flow around the ribs.

3. Parallel ribs angled at $45^{\circ}$ or $60^{\circ}$ relative to the internal crossflow direction result in a remarkable enhancement of the discharge coefficient compared to $75^{\circ}$ and $90^{\circ}$ ribs for both parallel and perpendicular orientations of internal crossflow and hole axis.

4. In a perpendicular arrangement, $45^{\circ}$ and $60^{\circ}$ angled ribs even outperform the non-ribbed case and thus could lead to an improved overall cooling performance.

5. Discharge coefficients for v-shaped ribs strongly depend on the rib angle, ranging from the lowest values found for parallel $90^{\circ}$ ribs to the highest values found for without ribs.

\section{REFERENCES}

1 Han, J.-C., Glicksman, L. R., and Rohsenow, W. M. An investigation of heat transfer and friction for ribroughened surfaces. Int. J. Heat Mass Transfer, 1978, 21, 1149-1156.

2 Park, J. S., Han, J.-C., Huang, Y., Ou, S., and Boyle, R. J. Heat transfer performance comparisons of five different rectangular channels with parallel angled ribs. Int. J. Heat Mass Transfer, 1992, 35, 2891-2903.

3 Han, J.-C., Park, J. S., and Lei, C. K. Heat transfer enhancement in channels with turbulence promoters. J. Eng. Gas Turbines Pwr, 107, 628-635.

4 Han, J.-C., Zhang, Y. M., and Lee, C. P. Augmented hear transfer in square channels with parallel, crossed, and v-shaped angles ribs. J. Heat Transfer, 1991, 113, 590-596.

5 Hay, N. and Lampard, D. Discharge coefficient of turbine cooling holes: A review. J. Turbomach., 120, 314-319. 
6 Burd, S. W. and Simon, T. W. Measurements of discharge coefficients in film cooling. J. Turbomach., 121, 243-248.

7 Hay, N., Lampard, D., and Benmansour, S. Effect of crossflow on the discharge coefficient of film cooling holes. J. Eng. Pwr, 1983, 105, 243-248.

8 Gritsch, M., Schulz, A., and Wittig, S. Effect of crossflow on the discharge coefficient of film cooling holes with varying angles of inclination and orientation. J. Turbomach., 123, 781-787.

9 Hay, N. and Lampard, D. The discharge coefficient of film cooling holes. ASME paper no. 95-GT-15, 1995.

10 Gritsch, M., Schulz, A., and Wittig, S. Discharge coefficient measurements of film cooling holes with expanded exits. ASME paper no. 97-GT-165, 1997.

11 Saumweber, S. and Schulz, A. Comparison of the cooling performance of cylindrical and fan-shaped cooling holes with special emphasis on the effect of internal coolant crossflow. ASME paper no. GT200851036, 2008.

12 Saumweber, S. and Schulz, A. Effect of geometry variations on the cooling performance of fanshaped cooling holes. ASME paper no. GT200851038, 2008.

13 Hay, N., Henshall, S. E., and Manning, A. Discharge coefficient of holes angeled to the flow direction. $J$. Turbomach., 116, 92-96.

14 Gritsch, M., Schulz, A., and Wittig, S. A method of correlating the discharge coefficient of film-cooling holes with crossflows at hole entry and exit. AIAA J, 36(6), 976-980.

15 Gritsch, M., Schulz, A., and Wittig, S. Effect of internal coolant crossflow orientation on the discharge coefficient of shaped film-cooling holes. J. Turbomach., 122, 146-152.

16 Rowbury, D. A., Oldfield, M. L. G., and Lock, G. D. A method for correlating the influence of external crossflow on the discharge coefficient of film cooling holes. J. Turbomach., 123, 258-265.

17 Wilfert, G. and Wolff, S. Influence of internal flow on film cooling effectiveness. ASME paper no. 99-GT25, 1999.

18 Kissel, H. P., Weigand, B., von Wolfersdorf, J., Neumann, S. O., and Ungewickell, A. An experimental and numerical investigation of the effect of cooling channel crossflow on film cooling performance. ASME paper no. GT2007-27102, 2007.

19 Bunker, R. S. and Bailey, J. C. Film cooling discharge coefficient measurements in a turbulated passage with internal crossflow. J. Turbomach., 2001, 123, 774-780.
20 Heneka, C., Schulz, A., and Bauer, H.-J. Effect of internal rib configurations on the discharge coefficient of a 30-degree inclined film cooling hole. J Heat Transfer, 2010, 41(10), 769-786.

21 Wittig, S., Schulz, A., Gritsch, M., and Thole, K. Transonic film-cooling investigations: Effects of hole shapes and orientation. ASME paper no. 96GT-222, 1996.

22 Kline, S. J. and McClintock, F. A. Describing uncertainties in single-sample experiments. Mech. Eng, 75, 3-8.

23 Acharya, S., Dutta, S., Myrum, T. A., and Baker, R. S. Periodically developed flow and heat transfer in a ribbed duct. Int. J. Heat Mass Transfer, 1993, 36, 2069-2082.

24 Ahn, J., Choi, H., and Lee, J. S. Large eddy simulation of flow and heat transfer in a channel roughened by square or semicircle ribs. ASME paper no. GT200453401, 2004.

\section{APPENDIX}

\section{Notation}

$c_{\mathrm{D}} \quad$ discharge coefficient

$D \quad$ film cooling hole diameter

e rib height

$h \quad$ height

$L \quad$ film cooling hole length

$\dot{m} \quad$ mass flux through film cooling hole

$\mathrm{Ma}$ Mach number

$p$ pressure

$P \quad$ rib pitch

$T$ temperature

$\mathrm{Tu}$ turbulence intensity

$w \quad$ width

$\alpha \quad$ hole inclination angle

$\beta \quad$ orientation angle

$\kappa \quad$ isentropic exponent

\section{Subscripts}

c internal flow conditions

h film cooling hole

m external flow conditions

t total conditions 


\section{Repository KITopen}

Dies ist ein Postprint/begutachtetes Manuskript.

Empfohlene Zitierung:

Heneka, C.; Schulz, A.; Bauer, H.-J.

Influence of internal parallel and v-shaped ribs on the discharge coefficient of a cylindrical film cooling hole.

2011. Proceedings of the Institution of Mechanical Engineers, Part A: Journal of Power and Energy, 225.

doi:10.5445/IR/1000040273

Zitierung der Originalveröffentlichung:

Heneka, C.; Schulz, A.; Bauer, H.-J.

Influence of internal parallel and v-shaped ribs on the discharge coefficient of a cylindrical film cooling hole.

2011. Proceedings of the Institution of Mechanical Engineers, Part A: Journal of Power and Energy, 225 (7), 985-994.

doi:10.1177/0957650911410926 